\title{
JENIS-JENIS KATAK (AMPHIBI: ANURA) DI DESA SUKA MAJU KECAMATAN TAMBUSAI KABUPATEN ROKAN HULU PROVINSI RIAU
}

\author{
Susan Anisa ${ }^{1 *}$, Arief Anthonius Purnama ${ }^{1}$, Ria Karno ${ }^{1}$ \\ ${ }^{1}$ Program Studi Pendidikan Biologi Fakultas Keguruan Dan Ilmu Pendidikan \\ Universitas Pasir Pengaraian \\ Jl. Tuanku Tambusai Kumu Desa Rambah Kecamatan Rambah Hilir. Pasir Pengaraian \\ *Email: susananisa81@gmail.com
}

\begin{abstract}
This research aims to determine the diversity of frog (Amphibians: Anura) in Desa Suka Maju Kecamatan Tambusai Kabupaten Rokan Hulu. This study was conducted from February to April 2018 by using visual encounter survay (capture directly to the survey) by the sampling technique samples by random sampling. Samples were collected with three repetitions at each station. The results, is three family, seven genera and eight species are Kaloula baleata, Rhacophorus margaritifer, Polypedates leucomystax, Humerana miopus, Chalcorana chalconata, Hylarana erythraea, Fejervarya limnocharis and Fejervarya cancrivora.
\end{abstract}

Keywords: Diversity, Frog, Anura.

\section{PENDAHULUAN}

Amphibi merupakan bagian dari komponen ekosistem yang berarti, baik secara ekologis ataupun ekonomis. Amphibi di Indonesia tercatat memiliki dua dari tiga ordo amphibi yang ada di dunia, yaitu Cecilia atau Gymnopiona dan Anura. Anura merupakan ordo terbesar dengan jumlah 5.208 spesies (Stuarte et al., 2008). Yang termasuk kategori Anura adalah katak dan kodok. Katak dikenal dengan tubuh yang khas, mempunyai empat kaki, mata yang cenderung besar, leher tidak jelas dan tidak memiliki ekor. Kaki belakang katak lebih panjang daripada kaki depan, yang digunakan untuk melompat agar terhindar dari pemangsa (Ario, 2010). Amphibi hidup di habitat aquatic dan teresterial, habitat aquatik meliputi sungai sedangkan habitat teresterial meliputi kebun masyarakat (Sari, Nurdjali, \& Erianto, 2014). Penyebaran anura sangat luas seperti di pepohonan, disepanjang aliran sungai dan pemukiman penduduk (Stuarte et al., 2008).
Katak merupakan kelompok hewan yang sangat peka terhadap perubahan lingkungan ataupun perubahan iklim. Perubahan lingkungan dampaknya sangat nyata terhadap jenis katak, hal ini dapat dilihat dari turunnya populasi disertai turunnya keragaman jenis katak. International Union for Conservation of Nature (IUCN) merupakan organisasi yang didedikasikan dalam hal konservasi SDA (Sumber Daya Alam). IUCN menetapkan kriteria sebagai evaluasi status kelangkaan spesies. IUCN bertujuan membantu komunitas di dunia dalam konservasi alam (IUCN, 2017).

Wanda, Novarino, \& Tjong, 2012 melaporkan sebanyak satu ordo, 5 famili dengan 10 genus yang memiliki 19 spesies dengan jumlah keseluruhan 127 individu di Hutan Harapan Jambi. Yudha, Eprilurahman, Trijoko, Alawi, \& Tarekat, 2014 melaporkan sebanyak 5 famili dengan 8 spesies anggota ordo Anura yang terletak di sungai Opak Provinsi Daerah Istimewa Yogyakarta. Ariza, Dewi, \& Darmawan, 2014 juga melaporkan sebanyak 5 famili dengan 15 spesies dengan total 105 
Anisa, S., Purnama, AA., Karno, R. 2018. Jenis-Jenis Katak (Amphibi: Anura) di Desa Suka Maju Kecamatan Tambusai Kabupaten Rokan Hulu Provinsi Riau. Sainstek : Jurnal Sains dan Teknologi. 10 (2) : 37-42

individu di Youth Camp Desa Hurun Kecamatan Padang Cermin Kabupaten Pesawaran. Putra, Rizaldi, \& Tjong, 2012 melaporkan sebanyak 14 jenis, 8 genus dan 3 famili dengan total 115 individu di Kawasan Hutan Harapan Jambi. Nola, Titrawani, \& Yusfiati, 2013 menemukan 13 jenis Ampibi ordo anura sebanyak 189 yang berada pada Kawasan Kampus Universitas Riau Pekanbaru. Winata, Anthonius Purnama, \& Karno, 2015 melaporkan di Desa Kepenuhan Hulu Kecamatan Kepenuhan Hulu Kabupaten Rokan Hulu Provinsi Riau, ditemukan 4 famili, 6 genus dan 10 spesies dengan total 114 individu.

Izza \& Kurniawan, 2014 melaporkan di air terjun Watu Ondo dan OWA Cagar ditemukan 5 jenis Amphibi dari ordo anura dengan 5 famili yang berbeda. Yani, Said, \& Erianto, 2015 melaporkan di kawasan Hutan Lindung Gunung Semahung Kecamatan Sengah Temila Kabupaten Landak Kalimantan Barat ditemukan 18 jenis amphibi dari 6 famili dengan jumlah keseluruhan 357 individu. Darmawan, 2008 melaporkan di kawasan Eks-HPH PT Rimba Karya Indah Kabupaten Bungo Provinsi Jambi ditemukan amphibi sebanyak 37 jenis; Nola et al., 2013 melaporkan pada Kawasan Kampus Universitas Riau Pekanbaru amphibi ordo anura ditemukan 13 jenis dengan jumlah total 189 individu.

Di Desa Suka Maju, Kecamatan Tambusai Kabupaten Rokan Hulu terdapat enam Dusun yakni Dusun Suka Karya 1, Dusun Suka Karya 2, Dusun Suka Mulya 1, Dusun Suka Mulya 2, Dusun Suka Sari 1 dan Dusun Suka Karya 2. Desa Suka Maju memiliki batas wilayah sebelah timur berbatasan dengan Tambusai Timur, sebelah selatan berbatasan langsung dengan Kecamatan Ramabah Hilir, sebelah barat berbatasan dengan Desa Tingkok dan sebelah utara berbatasan dengan PT Torganda. Spesies katak bertahan hidup ditempat lembab dan basah, contohnya air yang timbul di hutan pada musim hujan memiliki pengaruh terhadap pertumbuhan berudu katak dan sejenisnya. Di Desa Suka Maju ini belum pernah dilakukan penelitian mengenai jenisjenis katak (Amphibi: Anura). Berdasarkan latarbelakang tersebut dapat dilakukan penelitian dengan judul jenis-jenis katak
(Amphibi: Anura) di Desa Suka Maju Kecamatan Tambusai Kabupaten Rokan Hulu Propinsi Riau.

\section{METODE PENELITIAN}

Jenis penelitian ini adalah deskriptif kualitatif dengan menggunakan metode Visual Encounter Survei (tangkap langsung dengan survei). Beberapa peralatan yang akan digunakan adalah alat tulis, GPS (Global Position System), senter, jam, kamera digital dan tangguk. Bahan yang digunakan adalah kertas label, karet gelang, sarung tangan kain, kotak spesimen, botol spesimen, plastik ukuran $1 \mathrm{~kg}$, kapas, jarum suntik dan alkohol $70 \%$.

1. Di Lapangan

Pengambilan sampel dilakukan dua kali pengulangan untuk setiap stasiun dimulai dari jam 19:00 sampai jam 23:00 WIB, semua katak yang terlihat akan langsung dikoleksi dengan cara katak yang terlihat disinari dengan senter agar buta sesaat dan tidak meloncat. Penangkapan dilakukan dari bagian belakang katak dan ditangkap dengan menggunakan tangguk. Sampel yang didapat dimasukan ke dalam kantong plastik dengan menggunakan sarung tangan lalu diikat dengan karet gelang dan kemudian diberi label dengan mencatat nama lokal, waktu ditemukan, tempat, aktivitas dan habitat, pengambilan sampel dilakukan oleh 3 orang.

2. Di Laboratorium

Setelah sampel dibawa ke Laboratorium Pendidikan Biologi Program Studi Pendidikan Biologi Fakultas Keguruan dan Ilmu Pendidikan Universitas Pasir Pengaraian, maka sampel akan segera diidentifikasi dengan menggunakan buku identifikasi karangan (Darmawan, 2008), (Ario, 2010) dan (Bartlett, Billy, \& Bartlett, 2010). Setelah dilakukan identifikasi semua spesimen tersebut akan segera disimpan untuk dijadikan sebagai koleksi di Laboratorium Pendidikan Biologi Program Studi Pendidikan Biologi Fakultas Keguruan dan Ilmu Pendidikan Universitas Pasir Pengaraian 
Anisa, S., Purnama, AA., Karno, R. 2018. Jenis-Jenis Katak (Amphibi: Anura) di Desa Suka Maju Kecamatan Tambusai Kabupaten Rokan Hulu Provinsi Riau. Sainstek : Jurnal Sains dan Teknologi. 10 (2) : 37-42

Tabel 1. Jenis-jenis Katak (Amphibi: Anura) pada Desa Suka Maju

\begin{tabular}{|c|c|c|c|c|c|c|c|c|c|c|c|}
\hline \multirow{2}{*}{$\begin{array}{l}\mathrm{N} \\
\mathrm{o}\end{array}$} & \multirow{2}{*}{ Famili } & \multirow{2}{*}{ Genus } & \multirow{2}{*}{ Spesies } & \multirow{2}{*}{$\begin{array}{l}\text { Status } \\
\text { IUCN }\end{array}$} & \multicolumn{6}{|c|}{ Stasiun (Jumlah Individu) } & \multirow{2}{*}{ Total } \\
\hline & & & & & 1 & 2 & 3 & 4 & 5 & 6 & \\
\hline 1 & Microhylidae & Kaloula & Kaloula baleata & LC & 4 & - & 3 & 4 & - & 8 & 19 \\
\hline 2 & Rachophoridae & Rhacophorus & $\begin{array}{l}\text { Rhacophorus } \\
\text { margaritifer }\end{array}$ & LC & 1 & - & - & 1 & - & 1 & 3 \\
\hline 3 & Rachophoridae & Polypedates & $\begin{array}{l}\text { Polypedates } \\
\text { leucomystax }\end{array}$ & $L C$ & - & - & 2 & 2 & 1 & - & 5 \\
\hline 4 & Ranidae & Humerana & Humerana miopus & $L C$ & - & - & - & 2 & 1 & - & 3 \\
\hline 5 & Ranidae & Chalcorana & $\begin{array}{l}\text { Chalcorana } \\
\text { chalconata }\end{array}$ & LC & 1 & - & 1 & - & 1 & - & 3 \\
\hline 6 & Ranidae & Hylarana & $\begin{array}{l}\text { Hylarana } \\
\text { erythraea }\end{array}$ & $L C$ & - & - & 1 & 4 & 3 & 6 & 14 \\
\hline 7 & Ranidae & Fejervarya & $\begin{array}{l}\text { Fejervarya } \\
\text { limnocharis }\end{array}$ & LC & 6 & 2 & 5 & - & 3 & 4 & 20 \\
\hline \multirow[t]{2}{*}{8} & Ranidae & Fejervarya & $\begin{array}{l}\text { Fejervarya } \\
\text { cancrivora }\end{array}$ & $\mathrm{LC}$ & 3 & 1 & 2 & 4 & - & 5 & 15 \\
\hline & & & & & 15 & 3 & 14 & 17 & 9 & 24 & 82 \\
\hline
\end{tabular}

Keterangan:

LC: Least Concern

\section{HASIL DAN PEMBAHASAN}

Dari hasil penelitian yang telah dilakukan di Desa Suka Maju ditemukan 8 spesies yang tergolong kepada 3 famili dan 7 genus dengan jumlah individu sebanyak 82 individu. Jenisjenis Katak yang didapatkan terdapat pada Tabel 1. Pada Tabel 1 juga ditemukan tiga famili yaitu Microhylidae, Rachophoridae dan Ranidae. Pada family Microhylidae terdapat 1 spesies genus Kaloula hanya ditemukan 1 spesies yaitu Kaloula baleata, yang ditemukan di stasiun 1 berjumlah 4 individu, stasiun 4 berjumlah 3 individu, stasiun 4 berjumlah 5 individu dan stasiun 6 berjumlah 8 individu.

Untuk family Rachophoridae terdapat 2 genus yaitu Rhacophorus dan Polypedates. Pada genus Rhacophorus hanya ditemukan spesies Rhacophorus margaritifer, yang terdapat di stasiun 3, stasiun 4, dan stasiun 6 dengan jumlah masing-masing 1 individu. Untuk genus Polypedates hanya ditemukan spesies Polypedates leucomystax, yang tedapat di stasiun 3 berjumlah 2 individu, stasiun 4 berjumlah 2 individu dan stasiun 5 berjumlah 1 individu.

Untuk family Ranidae terdapat 4 genus yaitu Fajervarya, Hylarana, Humerana dan Chalcorana. Pada genus Fajervarna ditemukan spesies Fejervarya limnocharis dan Fejervarya cancrivora. Spesies Fejervarya limnocharis terdapat di stasiun 1 berjumlah 6 individu, stasius 2 berjumlah 2 individu, stasiun 3 berjumlah 5 individu, stasiun 5 berjumlah 3 individu dan stasiun 6 berjumlah 4 individu. Spesies Fejervarya cancrivora terdapat di stasiun 1 berjumlah 3 individu, stasiun 2 berjumlah 1 individu, stasiun 3 berjumlah 2 individu, stasiun 4 berjumlah 4 individu dan stasiun 6 berjumlah 5 individu.

Untuk genus Hylarana ditemukan spesies Hylarana erythraea yang terdapat di stasiun 3 berjumlah 1 individu, stasiun 4 berjumlah 4 individu, stasiun 5 berjumlah 3 individu dan stasiun 6 berjumlah 6 individu. Untuk genus Humerana ditemukan spesies Humerana miopus yang terdapat di stasiun 4 berjumlah 2 individu dan stasiun 5 berjumlah 1 individu. 
Anisa, S., Purnama, AA., Karno, R. 2018. Jenis-Jenis Katak (Amphibi: Anura) di Desa Suka Maju Kecamatan Tambusai Kabupaten Rokan Hulu Provinsi Riau. Sainstek : Jurnal Sains dan Teknologi. 10 (2) : 37-42

Berdasarkan Tabel 1. Individu terbanyak terdapat di stasiun 6 yang bertempat di perkebunan sawit yang ada kolam dan rawa dengan jumlah 24 individu. katak tidak bisa hidup jauh dari habitat akuatik. Salah satunya Spesies Hylarana erythraea biasa hidup habitat ini. Menurut Meijaard, Sheil, Nasi, Augeri, \& Rosenbaum, 2006 Pengembangbiakan anura sebagian besar terdapat pada habitat akuatik. Yani et al., 2015 mengatakan daerah akuatik lebih banyak terdapat individu dibandingan dengan daerah terestial.

Individu paling rendah terdapat di sekitar lapangan bola kaki yaitu stasiun 2 yang ditemukan 3 individu. Hal ini dikarenakan spesies ini tidak hidup di habitat aslinya. Menurut (Mistar, 2003) spesies ini berada di hutan sekunder dan hutan primer bahkan berada di genangan air atau air berarus lambat di pemukiman penduduk.

Spesies Fejervana limnocharis merupakan individu terbanyak yang ditemukan pada 6 stasiun yang ditemukan 20 individu. Spesies ini ditemukan pada 5 stasiun dari 6 stasiun. Spesies ini terdapat di perkebunan sawit, kolam dan rawa. Darmawan, 2008 menjelaskan bahwa spesies ini hidup pada air tergenang, juga terdapat pada hutan sekunder, bekas tambang dan kebun sawit. Iskandar, 1998 menyampaikan spesies ini terdapat di genangan, sawah, danau, telaga dan di dataran rendah (biasanya kurang dari $250 \mathrm{~m} \mathrm{dpl}$ ).

Berdasarkan Status IUCN pada Tabel 2, bahwa seluruh spesies ordo Anura yang teridentifikasi di kawasan Desa Suka Maju termasuk ke dalam kategori Least Concern (LC). Dari data tersebut dapat diperoleh informasi bahwa Ordo Anura yang terdapat pada Desa Suka Maju tidak ada yang tergolong kritis.

Adapun jenis-jenis katak yang ditemukan di kawasan Desa Suka Maju sebanyak 8 spesies (lihat Gambar 1).

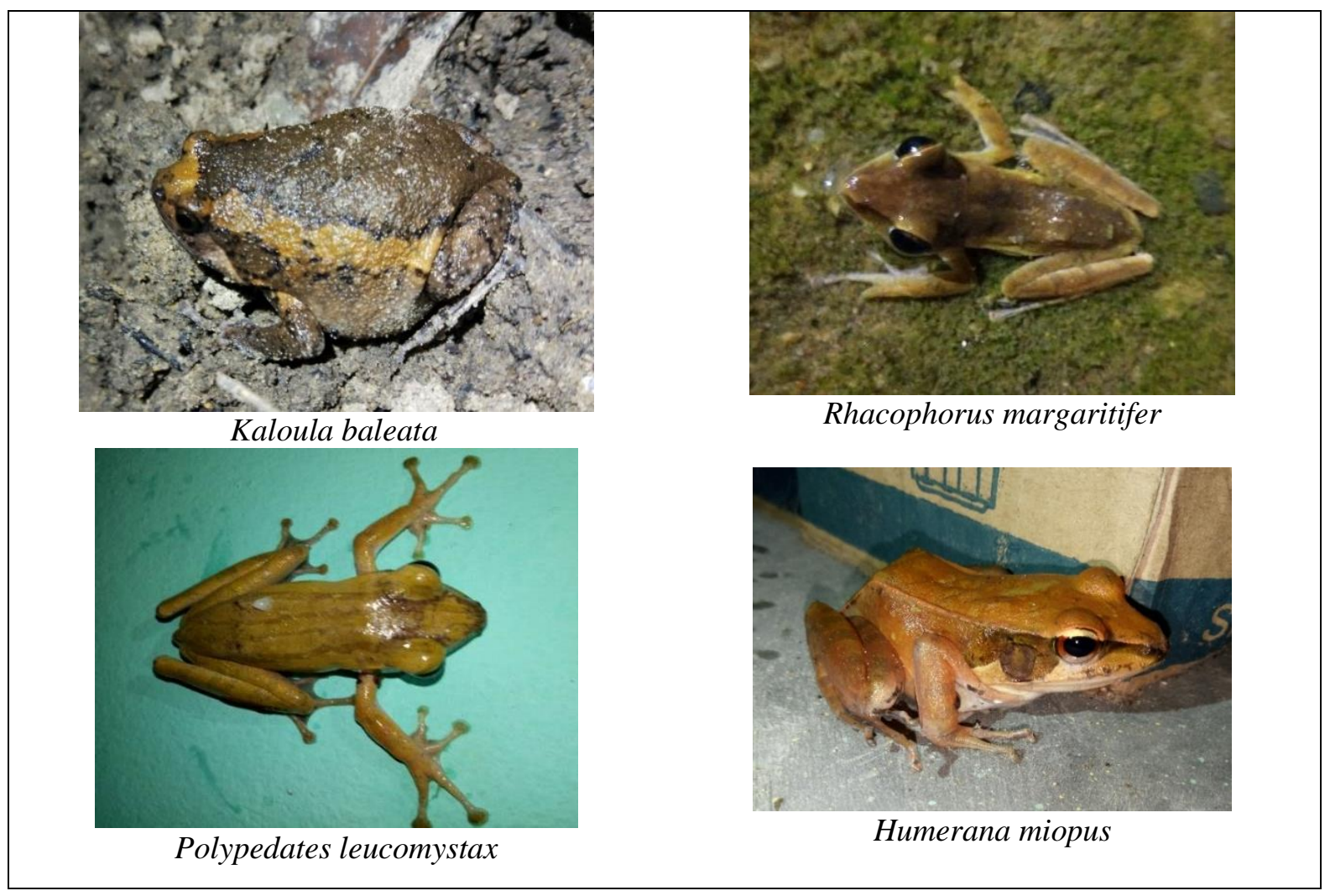




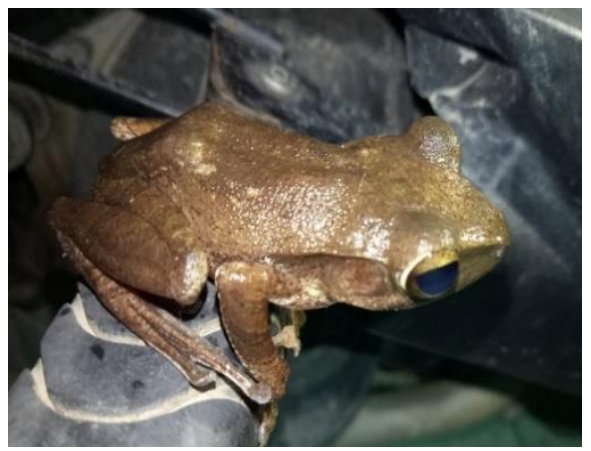

Chalcorana chalconata

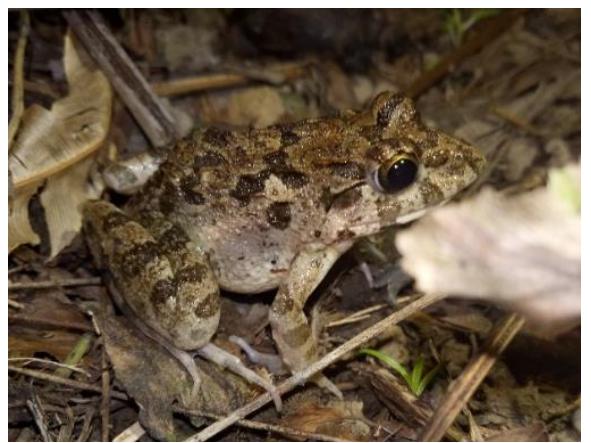

Fejervarya limnocharis

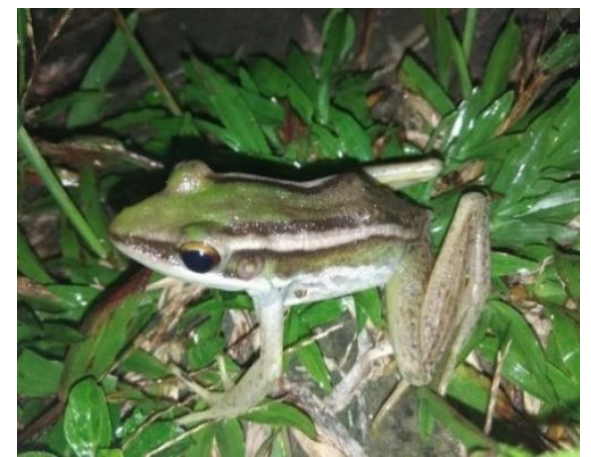

Hylarana erythraea

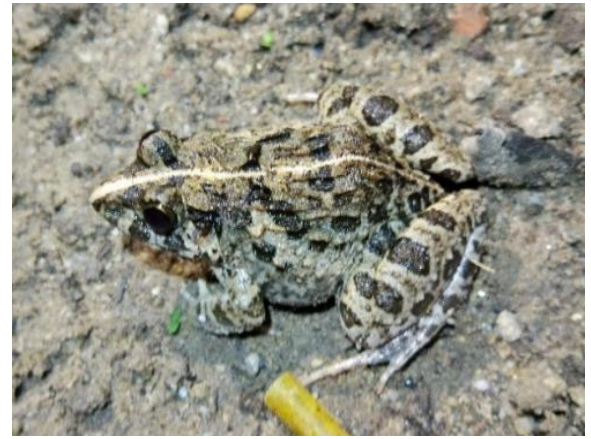

Fejervarya cancrivora

Gambar 1. Jenis-Jenis Katak di Kawasan Desa Suka Maju

\section{KESIMPULAN}

Berdasarkan Penelitian dapat diambil kesimpulan bahwa di Desa Suka Maju Kecamatan Tambusai ditemukan 8 spesies katak yang terdiri dari Kaloula baleata (19 individu), Rhacophorus margaritifer (3 individu), Polypedates leucomystax (5 individu), Humerana miopus (3 individu), Chalcorana chalconata (3 individu), Rana erythraea (14 individu), Fejervarya limnocharis (20 individu) dan Fejervarya cancrivora (15 individu).

\section{DAFTAR KEPUSTAKAAN}

Ario, A. (2010). Panduan Lapangan Satwa Taman Nasional Gunung Gede Pangrango. Jakarta: Conservation
International Indonesia.

Ariza, Y. S., Dewi, B. S., \& Darmawan, A. (2014). Keanekaragaman Jenis Amfibi (Ordo Anura) pada Beberapa Tipe Habitat di Youth Camp Desa Hurun Kecamatan Padang Cermin Kabupaten Pesawaran. Jurnal Sylva Lestari, 2(1), 21-30.

Bartlett, P., Billy, G., \& Bartlett, R. (2010). Reptiles, Amphibians and Invertebrates. China: Barron's Education.

Darmawan, B. (2008). Keanekaragaman Amfibi Di Berbagai Tipe Habitat: Studi Kasus Di Eks-Hph Pt Rimba Karya Indah Kabupaten Bungo, Provinsi Jambi.

Iskandar, D. T. (1998). Amfibi Jawa dan BaliSeri Panduan Lapangan. Bogor: Puslitbang LIPI.

IUCN. (2017). Guidelines for the application of IUCN Red List of Ecosystems Categories 
and Criteria. Version 13. Gland, Switzerland and Cambridge, UK: IUCN.

Izza, Q., \& Kurniawan, N. (2014). Eksplorasi Jenis-Jenis Amfibi di Kawasan OWA Cangar dan Air Terjun Watu Ondo Gunung Welirang, TAHURA R.Soejo. In Jurnal Biotropika (Vol. 2).

Meijaard, E., Sheil, D., Nasi, R., Augeri, D., \& Rosenbaum, B. (2006). Hutan pasca pemanenan: melindungi satwa liar dalam kegiatan hutan produksi di Kalimantan. Jakarta: Subur Printing.

Mistar. (2003). Panduan lapangan amfibi kawasan ekosistem Leuser. The Gibbon Foundation \& PILINGO Movement.

Nola, A., Titrawani, \& Yusfiati. (2013). Keanekaragaman Ordo Anura di Kawasan Kampus Universitas Riau Pekanbaru. E- Jurnal Mahasiswa FMIPA FKIP Universitas Riau Pekanbaru.

Putra, K., Rizaldi, \& Tjong, D. H. (2012). Komunitas Anura (Amphibia) pada Tiga Tipe Habitat Perairan di Kawasan Hutan Harapan Jambi Community of Anura (Amphibia) in three types of wetland habitat at the Harapan Rainforest Jambi. In Jurnal Biologi Universitas Andalas (J. Bio. UA.) (Vol. 1).

Sari, I. N., Nurdjali, B., \& Erianto. (2014). Keanekaragaman Jenis Ampibi (Ordo Anura) dalam Kawasan Hutan Lindung Gunung Ambawang Kecamatan Kubu
Kabupaten Kubu Raya. Jurnal Hutan Lestari, 2(1), 110-125.

Stuarte, S., Michael, H., Janice, C., Neil, C., Richard, B., Pavithra, R., \& Bruce, Y. (2008). Threatened amphibians of the world. USA: Conservation International.

Wanda, I. F., Novarino, W., \& Tjong, D. H. (2012). Jenis-Jenis Anura (Amphibia) Di Hutan Harapan, Jambi The. Jurnal Biologi Universitas Andalas, 1(2), 99107.

Winata, E. Y., Anthonius Purnama, A., \& Karno, R. (2015). Jenis-Jenis Katak (Amphibi: Anura) di Desa Kepenuhan Hulu Kecamatan Kepenuhan Hulu Kabupaten Rokan Hulu Provinsi Riau. EJurnal Mahasiswa Prodi Biologi FKIP Unversitas Pasir Pangaraian, 1-5.

Yani, A., Said, S., \& Erianto. (2015). Keanekaragaman Jenis Amfibi Ordo Anura di Kawasan Hutan Lindung Gunung Semahung Kecamatan Sengah Temila Kabupaten Landak Kalimantan Barat. Jurnal Hutan Lestari, 3(1), 15-20.

Yudha, D. S., Eprilurahman, R., Trijoko, Alawi, M. F., \& Tarekat, A. (2014). Keanekaragaman Jenis Katak dan Kodok (Ordo Anura) di Sepanjang Sungai Opak Propinsi Daerah Istimewa Yogyakarta. Jurnal Biologi, 18(2), 52-59. 